\title{
Spinal cord ultrasonography of the newborn
}

\author{
lacopo Valente ${ }^{1}$ (D) Alessandro Pedicelli ${ }^{1}$ - Martina Piacentini ${ }^{2} \cdot$ Marco Di Serafino $^{3}$. Gianfranco Vallone ${ }^{4}$. \\ Stefania Speca ${ }^{2} \cdot$ Cesare Colosimo $^{1,2}$
}

Received: 13 September 2018 / Accepted: 30 November 2018 / Published online: 7 December 2018

(c) Società Italiana di Ultrasonologia in Medicina e Biologia (SIUMB) 2018

\begin{abstract}
Ultrasound represents the first-line survey for the assessment of spinal cord development abnormalities. In fact, within 6 months of life, the non-ossification of neuronal arcs provides an excellent acoustic window that allows a detailed depiction of the spinal canal, its content and of the surrounding soft tissues. Nevertheless, an accurate ultrasound examination requires a complete knowledge of the anatomy, the condition of normality, the frequent anatomical variants and the main pathologies involved. This review is intended to briefly summarize the US technique, the main clinical indication and the key notions that could help to properly perform this type of ultrasound examination.
\end{abstract}

Keywords Innovative biotechnologies $\cdot$ Ultrasound $\cdot$ Spinal dysraphisms $\cdot$ Tethered cord syndrome

\section{Sommario}

L'ecografia rappresenta l'indagine di prima linea per la valutazione delle anomalie dello sviluppo del midollo spinale. Infatti, entro i sei mesi di vita, la mancata ossificazione degli archi neurali offre un'eccellente finestra acustica che permette una dettagliata valutazione del canale spinale, del suo contenuto e dei tessuti molli circostanti. Tuttavia, un'accurata valutazione ecografica non può prescindere da una completa conoscenza dell' anatomia, delle condizioni di normalità, delle frequenti varianti anatomiche e delle principali patologie. Questa review ha lo scopo di riassumere brevemente la tecnica ecografica, le principali indicazioni cliniche e le nozioni chiave che potrebbe aiutare per eseguire correttamente questo tipo di indagine.

\section{Introduction}

Since the 1980s, ultrasound (US) has been the first-line imaging modality to investigate the spinal canal and its contents in the pediatric setting [1].

The cartilaginous posterior elements of the neonatal spine offer a good "acoustic window" up to approximately

Iacopo Valente

iacopovalentemd@gmail.com

1 UOC Radiologia e Neuroradiologia, Dipartimento di diagnostica per immagini, Radioterapia Oncologica ed Ematologia, Fondazione Policlinico Universitario A. Gemelli IRCCS, L.go F. Vito 1, 00168 Rome, Italy

2 Istituto di Radiologia, Università Cattolica del Sacro Cuore, Rome, Italy

3 UOSC Radiologia Generale e PS, AORN Antonio Cardarelli, Naples, Italy

4 Dipartimento di Radiologia Pediatrica, AOU Federico II, Naples, Italy
6 months of age [2]. The main advantage of this technique is that it does not need any sedation or general anesthesia, which can damage the central nervous system of young infants [3].

The following clinical findings are the indications for an US screening examination in newborns [4]:

- Cutaneous lesions of the back (e.g., hypertrichosis, sacral sinus, subcutaneous lipoma),

- Deformities of the spine (e.g., scoliosis, malformations of the sacrum),

- Neurologic disturbances (e.g., paresis, neurogenic bladder or bowel dysfunction),

- Suspected spinal cord injury during child delivery,

- Syndromes with associated spinal cord compression.

More than $86 \%$ of spinal dysraphisms are associated with overlying cutaneous stigmata [5]. Simple solitaire sacral dimples in asymptomatic neonates consisting of a single midline dimple that measures less than $5 \mathrm{~mm}$ in diameter, 
located no more than $25 \mathrm{~mm}$ above the anal opening, have an extremely low associated risk of spinal malformations [6]. In fact, in one study including 160 infants with isolated simple sacral dimples, none showed underlying occult spinal dysraphisms identified on spinal ultrasonography [7]. The probability is only $0.34 \%$ [8]. Considering this very low risk, recent guidelines state that simple sacral dimples do not need further imaging evaluation, only when they are atypical, multiple, or in combination with other cutaneous stigmata [5].

The US examination can exclude significant pathologic conditions; moreover, in patients with normal findings, further imaging examinations are unnecessary. On the contrary, patients with US-detected spinal malformations must undergo further imaging examination (magnetic resonance $[\mathrm{MR}]$ ), which can be performed at the time of the elective surgical intervention [4].

Spinal dysraphisms represent a broad spectrum of congenital disorders resulting from impaired structural development along the craniospinal axis during the brain and spinal cord growth within weeks 2 and 6 of gestation and proceed through a complex multistep process [9].

Open or large spinal dysraphisms are easily recognized, whereas closed or smaller anomalies may present only as cutaneous abnormalities overlying the defect [2]. By rapidly and easily detecting these anomalies, US can present the correct diagnostic process of the patient.

\section{Ultrasonographic aspects and technique}

Lumbar spine ultrasonography studies are usually performed with the infant in a lying prone position with the spine curved over a pillow, with the upper body higher than the lower part (that is, flexed). This position offers a better acoustic window because of the lumbar cistern distention made by the consequent liquor gathering; liquor then separates the structures from each other. The examination is typically performed following a feeding, which usually ensures a quiet infant.

Spinal US is performed with a high-resolution (10-14 MHz) linear transducer through longitudinal and axial plane scans of the entire back, from the craniocervical junction to the tip of the coccyx $[10,11]$.

The main structures that must be identified and evaluated are (Figs. 1,2) the following:

1. conus medullaris,

2. filum terminale,

3. cauda equina,

4. central echo complex,

5. subarachnoid space.

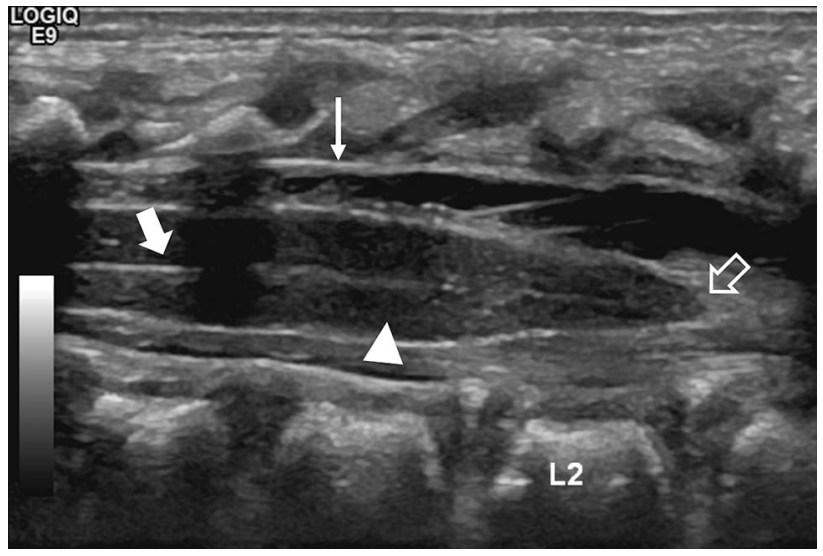

Fig. 1 Median longitudinal scan of the lumbosacral region showing the hypoechoic spinal cord (arrowhead), the central echo complex (arrow), the dura mater (thin arrow), and the medullary cone (empty arrow)

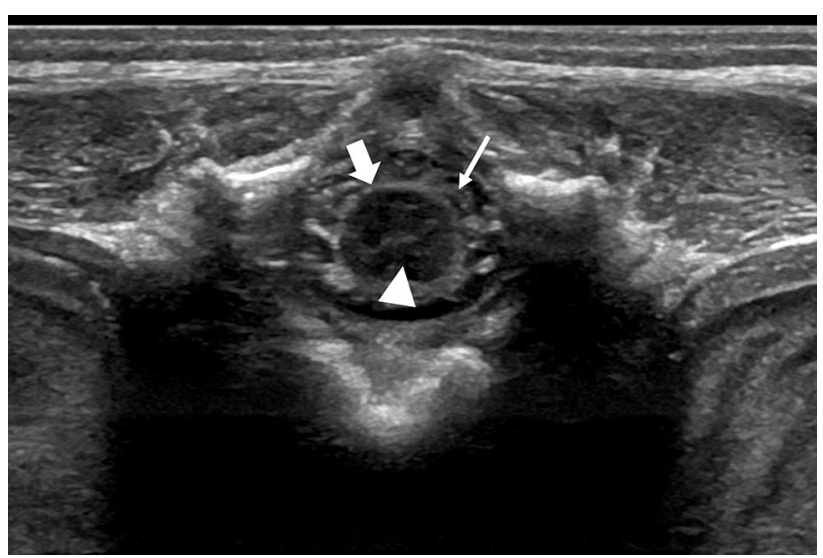

Fig. 2 Transversal scan of the lumbosacral area showing the spinal cord (arrowhead) in the axial plane with the dura mater (arrows) and the nerve roots (thin arrow)

\section{Conus medullaris}

The conus tip position in newborns is usually located between the L1 and L2 interspace and occasionally extends to the superior end plate of L3 (Fig. 3). To evaluate the correct position of the conus tip, we can apply the following three methods:

1. Identify the lumbosacral junction and then retrogradely count the lumbar vertebrae. The first sacral vertebra can be determined as the first vertebral body that tilts dorsally from a line described by all the other lumbar somas (Fig. 4). The correct positioning of the patient is important since a lordotic position would erase this deviation of the first sacral soma. 


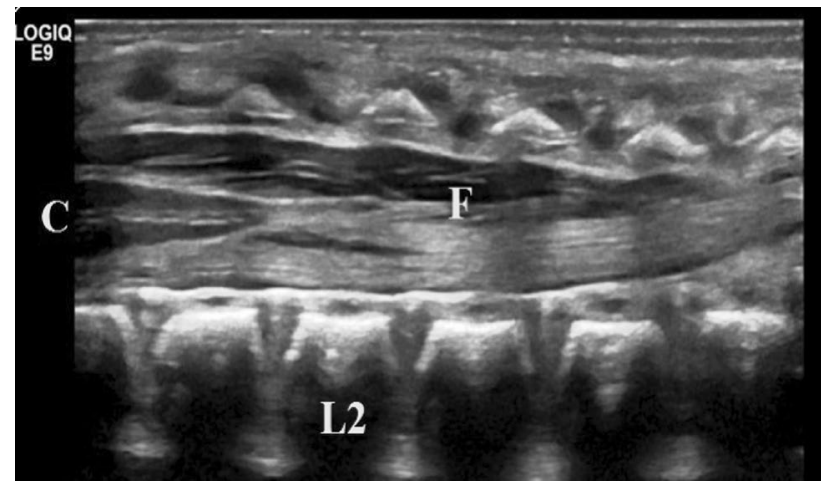

Fig. 3 Median longitudinal scan of the lumbosacral region showing the filum terminale $(\mathrm{F})$, the central echo complex $(\mathrm{C})$, and the L2 vertebral body

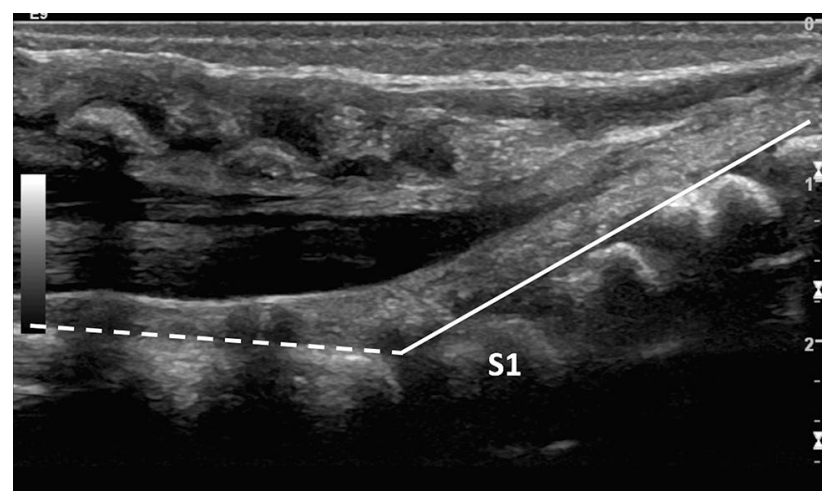

Fig. 4 Median longitudinal scan of the lumbosacral region showing the line that follows the posterior walls of the lumbar vertebral somas (dashed line) and the line that follows the posterior walls of the sacral vertebral somas (continuous line). The first sacral soma (S1) is the first that deviates from the dashed line

2. Identify the last rib-bearing vertebra (T12) and then count from above to $\mathrm{S} 1$.

3. Identify the coccyx (usually unossified or round shaped) and count superiorly from it (Fig. 5).

Our suggestion is to integrate all these methods to overcome all the limits offered by each approach.

\section{Filum terminale}

The filum terminale is a band of fibrous tissue that extends from the conus to the caudal end of the spinal canal. It should be less than $2 \mathrm{~mm}$ thick (measured on the L5-S1 level, Fig. 6), and its echostructure should be predominantly hypoechoic with a bright "train-line" hyperechoic periphery due to the liquor interface.

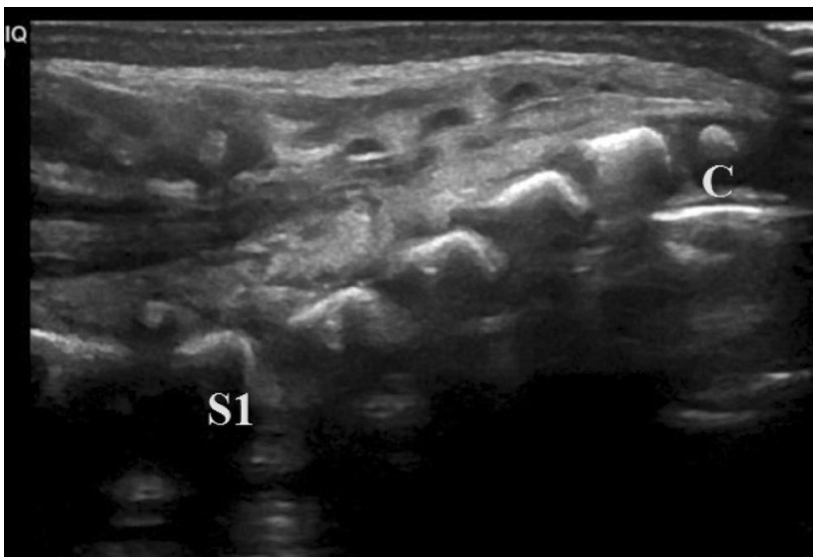

Fig. 5 Median longitudinal scan of the sacral region showing the round shape of a coccyx soma (C) and the rectangular shape of the sacral somas

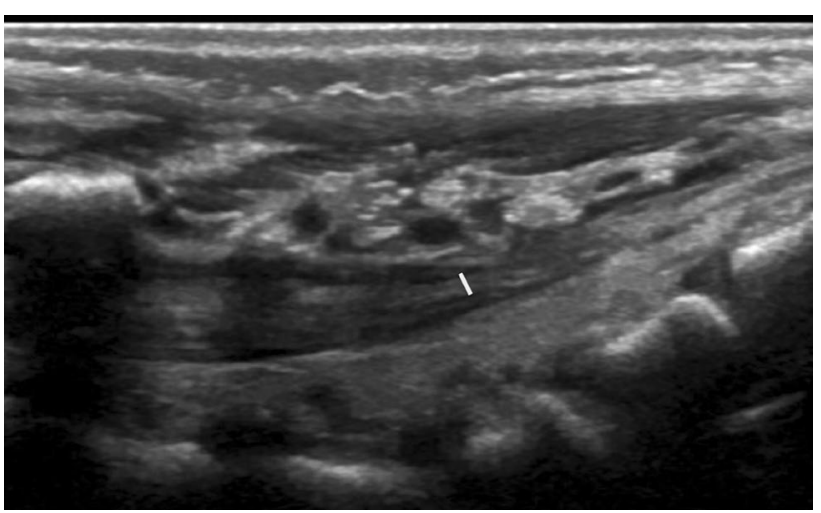

Fig. 6 Median longitudinal scan showing the filum terminale and the measurement of its thickness

\section{Cauda equina and spinal roots}

The cauda equina and the spinal roots must move according to the input provided by the pulsatile production of liquor. Unlike other imaging modalities, ultrasonography has the advantage of providing live images of the observed structures.

\section{Central echo complex}

The train-line hyperechogenicity provided by the interface of the two margins of the central canal is known as central echo complex (Fig. 1). It must be detectable at all levels of the spinal cord, and the space between the two hyperechoic stripes must be regular along its entire extension. 


\section{Subarachnoid space}

The subarachnoid space must be anechoic and must not contain other structures except for the spinal cord and the nerve roots.

\section{Normal anatomical variants}

The following are some common anatomical variants that should be known to prevent unnecessary alarmism and useless follow-up imaging or clinical evaluation:

- Ventriculus terminalis persistence (also known as fifth ventricle) (Fig. 7) refers to a mild cystic dilatation of the terminal spinal cord canal caused by the incomplete regression of embryonic ventriculus terminalis in the conus medullaris $[11,12]$; despite being frequently asymptomatic, low-back pain, sciatica, and bladder disorders have been reported [13]. Some authors include this anomaly into simple dysraphic states [14].

- Transient dilatation of the central canal usually disappears during the first weeks after birth [15].

- Filar cysts (Fig. 8) appear as a well-defined anechoic lesion within the filum terminale, immediately caudal to the cone, and do not have a clear clinical correlate.

- Mild thickening of the filum terminale $(>1 \mathrm{~mm}$ and $<2 \mathrm{~mm}$ ).

- Coccyx malformations with palpable prominence in the sacral region.

- Mild thickening of the epidural fat (Fig. 9).

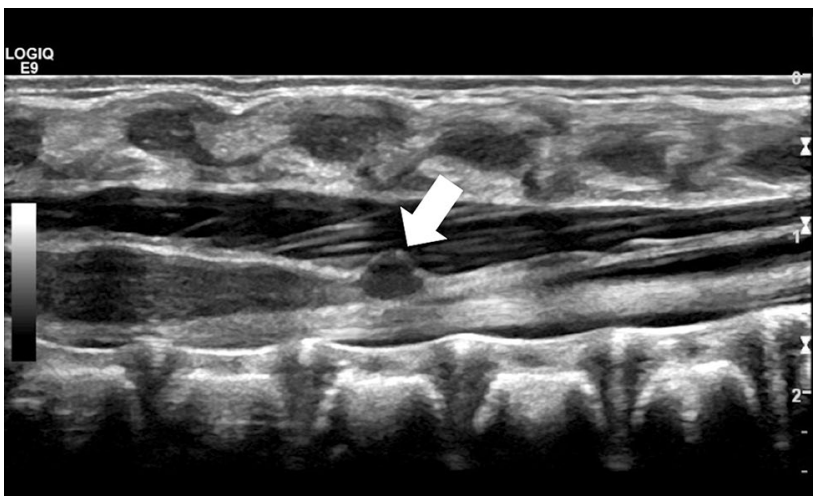

Fig. 8 Median longitudinal scan showing a focal anechoic cyst of the filum terminale, just caudally to the conus

\section{Pathology}

Spinal dysraphism refers to a wide spectrum of clinical findings concerning incomplete fusion of the midline neural and bony structures during early embryogenesis [16]. According to the classification proposed by Tortori-Donati et al., spinal dysraphisms should be divided into closed spinal dysraphisms (CSD) and open spinal dysraphisms (OSD). For an easier approach, we report a shorter and revised version of this classification:

- Closed spinal dysraphisms (CSD, also known as occult spinal dysraphism or spina bifida occulta) refer to a broad range of skin-covered congenital anomalies caused by failure of fusion of the neural tube that may cause progressive neurological deterioration.

- CSD without subcutaneous mass

- Tethered cord syndrome

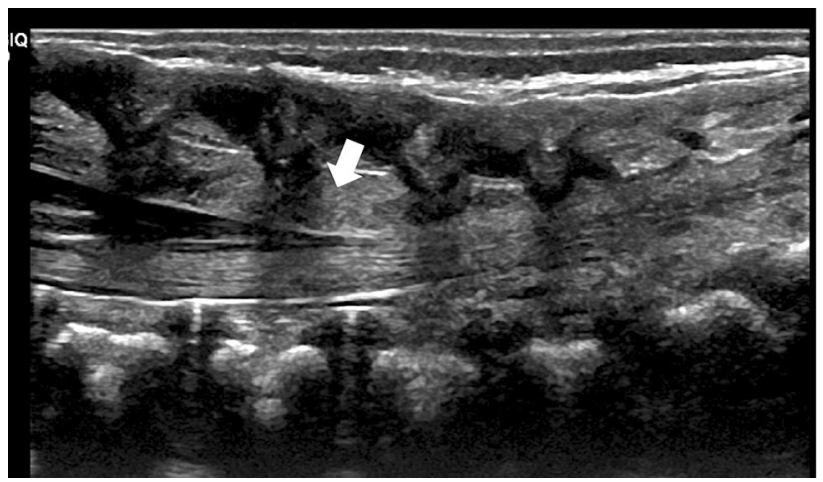

Fig. 9 Median longitudinal scan showing a prominent isoechoic epidural fat (arrowhead)
Fig. 7 Median longitudinal scan showing a ventriculus terminalis (a.k.a. fifth ventricle, arrow), which is a focal distension of the central canal

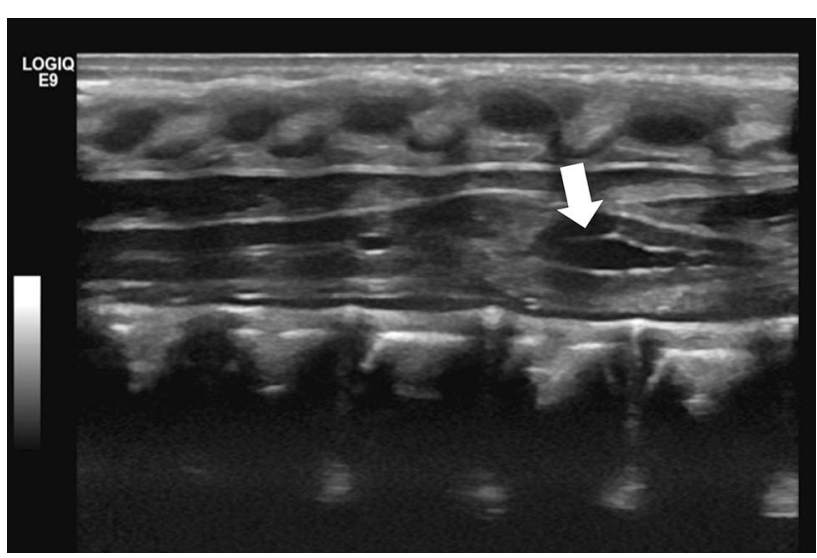


- Dermal sinus

- Diastematomyelia

- Spinal lipoma.

- CSD with subcutaneous mass

- Lipomyelomeningocele

- Lipomyelocele

- Terminal myelocystocele

- Meningocele

- Nonterminal myelocystocele.

- Open spinal dysraphisms (OSD) refer to developmental anomalies uncovered with skin caused by a missed closure of the neural tube during primary neurulation. Since the alteration is visible in the antenatal US and during a simple clinical inspection, US can be employed to investigate the presence of associated anomalies and in post-operatory follow-up.

- Myelomeningocele

- Myelocele

- Hemimyelomeningocele

- Hemimyelocele.

\section{Tethered cord syndrome}

Tethered cord syndrome (TCS) was first described in 1953 [17], and it is characterized by neurological, urological, and orthopedical deficits due to ischemia of the lower conus caused by traction of the spinal cord during growth.

US imaging is a valid screening method for tethered cord, with $96 \%$ sensitivity and $96 \%$ specificity [18].

TCS must be suspected when the conus terminates below the superior aspect of L3 vertebral body (often beneath L3) and it is displaced dorsally in the spinal canal. A thickened filum terminale may be associated. The lack of nerve root mobility is also an important sign, especially for older kids, who may show a cone in the right place but with reduced nerve root movements (minimal tethered cord syndrome). Nonetheless, it is important to remember that vertebral counting can be incorrect; thus, we suggest executing all the counting methods previously exposed. MRI is suggested in case of US evidence of TCS or in case of doubts.

\section{Dermal sinus}

The dermal sinus, a median/paramedian epithelial duct running from the skin to the spinal cord, is due to an incomplete separation of the ectoderm from the neural crest, causing persistent communication between the two surfaces. On inspection, it appears as a small pit in the lumbosacral area, often associated with other cutaneous anomalies such as hyperpigmentation, angiomatosis, or local/regional hypertrichosis. It can sometimes appear in association with neurological deficits and central nervous system (CNS) infections. (Germs can spread from the skin surface to the spinal canal, causing intraspinal abscesses and meningitis.)

US can show the entire length of the tract. The subcutaneous part of the sinus is usually hypoechoic, and the hyperechoic subcutaneous fat offers a useful background; instead, the subarachnoid tract can be identified over the liquor.

The epithelial duct can finish

- in the soft tissue overlying the spinal canal (6-7\% of all cases),

- in the epidural space (10-20\% of all cases), and

- in the dural sac $(60 \%$ of all cases. In $50 \%$ of these cases, the dural sac terminates directly against the medullary cone, cauda equina, or terminal filum).

The most common condition that can possibly mimic a dorsal dermal sinus is the sacral-coccygeal sinus [19]. However, low sacral/coccygeal sinuses have a different embryological origin and terminate in the sacral/coccygeal fascia but never extend into the subarachnoid space. Nonetheless, differential diagnosis with such lesion can be performed with the observation of few distinctive characteristics of the dimple that is associated with a dermal sinus:

- localization above the intergluteal space

- size $>5 \mathrm{~mm}$

- caudal orientation

- association with other dermal anomalies suggesting spinal dysraphisms.

\section{Diastematomyelia}

Diastematomyelia, also known as a split cord malformation, refers to a type of CSD characterized by a longitudinal split in the spinal cord. It accounts for $\sim 5 \%$ of all congenital spinal defects, and 50\% occurs between L1 and L3 and 25\% occurs between $\mathrm{T} 7$ and $\mathrm{T} 12$, with up to $85 \%$ from $\mathrm{T} 9$ to L5 [20].

Diastematomyelia is divided into two types according to the presence of a dividing septum and single or double dural sac: type I, with a duplicated dural sac and common midline spur and usually symptomatic; and type II, with a single dural sac containing both hemicords. The cord must be explored through the axial plane in addition to the longitudinal plane, because the two separate cords are easier to identify (Fig. 10). 


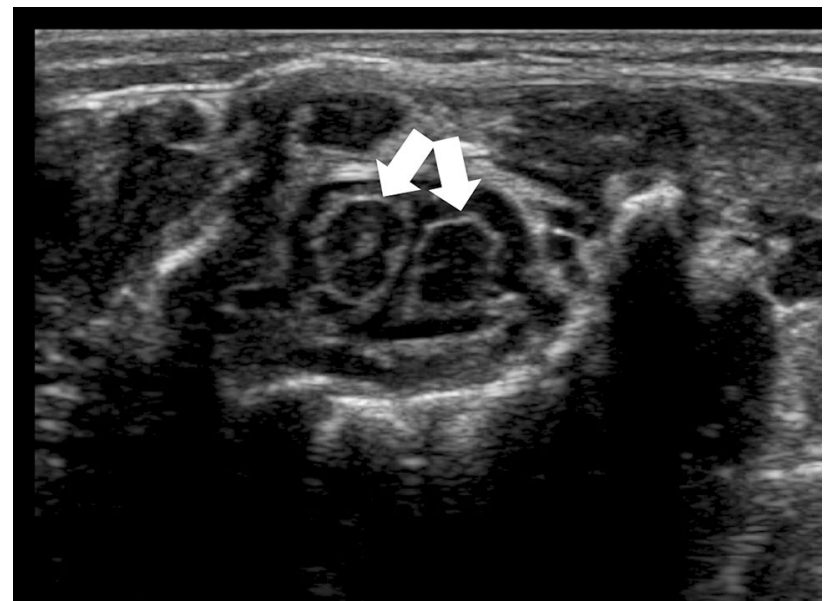

Fig. 10 Axial scan of the lumbar region showing a diastematomyelia (arrows)

\section{Spinal lipoma}

Spinal lipomas are caused by premature separation of the ectoderm from the neural crest inducing mesenchymal cells to get trapped and stick within the spinal cord. Spinal lipomas can be intradural, extradural, or a combination of both [15]. They are not entirely made of fat, but they also contain neural tissue and meninges [16]. On US, these lesions appear as uniformly echogenic masses. Since the fat cells can strongly increase in size during infancy, these lesions can significantly expand later in life.

There are three types of lipoma:

- Fibrolipoma of the filum terminale is a $>2 \mathrm{~mm}$-thick hyperechoic filum terminale that can be associated with TCS.

- Intradural lipoma (Fig. 11) are usually lumbosacral and associated with TCS, whereas cervicothoracic lipomas are frequently present later with signs of spinal cord compression. They lie along the midline within a completely formed dural sac [20].

- Lipomyelomeningocele and lipomyelocele present as a lumbar subcutaneous fat-containing mass, typically beginning cephalad to the gluteal cleft and extending caudally, often in an asymmetrical position.

Another defect included into the CSD is the terminal myelocystocele, which represents a CSD in which the dilated central canal of the spinal cord protrudes dorsally into the dorsal subcutaneous tissues; the cord terminates in a cyst that communicates with the central canal of the spinal cord.

Open spinal dysraphisms (OSD), such as myelomeningocele and myelocele, are skin-uncovered developmental anomalies. Since they are clearly appreciated during the antenatal US or a physical examination, they are not
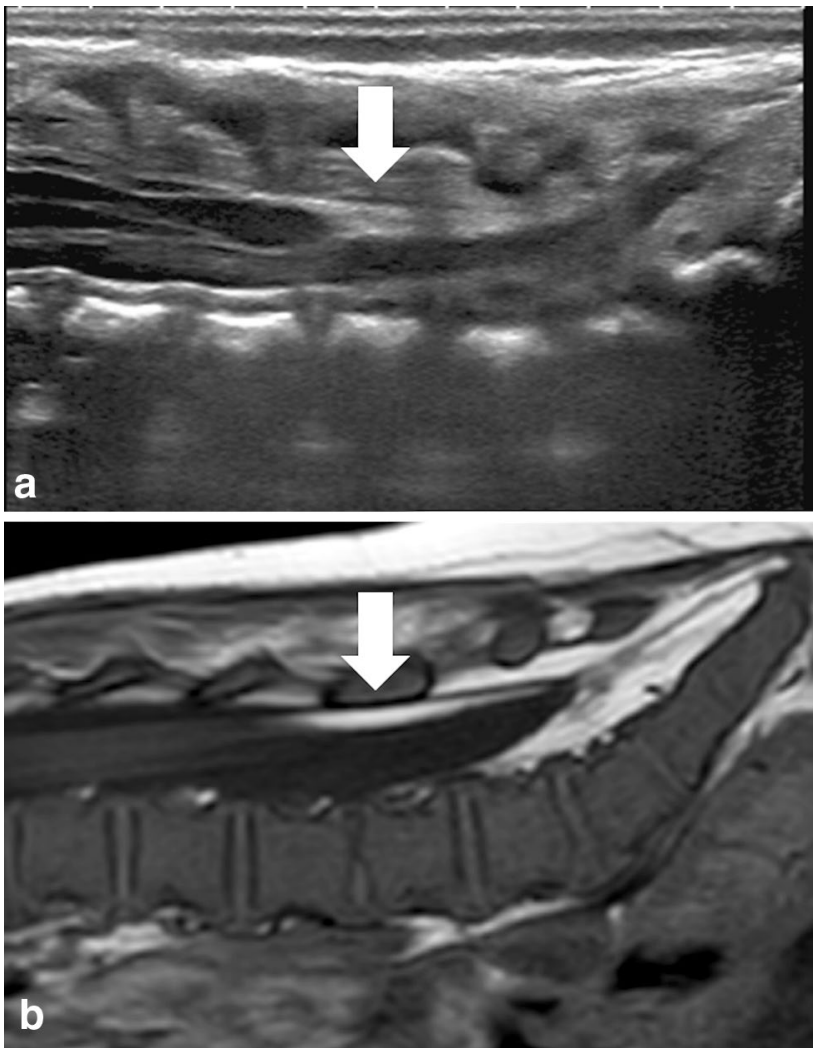

Fig. 11 a Median longitudinal scan of the lumbosacral region showing a hyperechoic intradural lipoma of the dorsal aspect of the spinal canal. b Median longitudinal scan of a T1w MRI image showing the same intradural lipoma

typically a diagnostic challenge. More clinically relevant diagnostic concerns include the extent of any associated Chiari II malformation, any concomitant hydrocephalus, and any potential complications following surgical closure $[21,22]$.

\section{Conclusion}

In this review, we summarized the indications, technique, normal anatomy, and normal variants identified on neonatal spine ultrasonography. We focused on the most commonly found anomalies of the lumbosacral region.

In the newborn, the US examination is the first-line imaging modality to investigate the spinal canal and its contents since it can exclude significant pathologic conditions. Moreover, an extensive knowledge of the spine anatomy and pathology is needed to understand when a spinal ultrasound is indicated and to prevent any unnecessary examinations.

Nevertheless, patients with spinal malformations detected by US must undergo an MR examination that can better depict the pathologic condition, identify any associated 
anomalies, and help the surgeon plan a safe and effective therapeutic approach.

\section{Compliance with ethical standards}

Conflict of interest The authors declare that there is no conflict of interest.

Ethical approval According to our National and Institutional regulations, retrospective analysis of anonymized dataset does not require ethics committee review.

Informed consent No informed consent was collected as only routine diagnostic examinations were performed. All images were appropriately anonymized.

\section{References}

1. Miller J, Reid B, Randall Kemberling C (1982) Utilization of ultrasound in the evaluation of spinal dysraphism in children. Radiology 143:737-740

2. Chern JJ, Kirkman JL, Shannon CN, Tubbs RS, Stone JD, Royal SA, Oakes WJ, Rozzelle CJ, Wellons JC (2012) Use of lumbar ultrasonography to detect occult spinal dysraphism. J Neurosurg Pediatr 9:274-279. https://doi.org/10.3171/2011.12.PEDS11351

3. McCann ME, Soriano SG (2009) Is anesthesia bad for the newborn brain? Anesthesiol Clin 27:269-284. https://doi. org/10.1016/j.anclin.2009.05.007

4. Ausili E, Maresca G, Massimi L, Morgante L, Romagnoli C, Rendeli C (2018) Occult spinal dysraphisms in newborns with skin markers: role of ultrasonography and magnetic resonance imaging. Child's Nerv Syst 34:285-291. https://doi.org/10.1007/s0038 1-017-3638-0

5. Zywicke HA, Rozzelle CJ (2011) Sacral Dimples. Pediatr Rev 32:109-114. https://doi.org/10.1542/pir.32-3-109

6. Kucera JN, Coley I, O'Hara S, Kosnik EJ, Coley BD (2014) The simple sacral dimple: diagnostic yield of ultrasound in neonates. Pediatr Radiol 45:211-216. https://doi.org/10.1007/s0024 7-014-3110-1

7. Kriss VM, Desai NS (1998) Occult spinal dysraphism in neonates: assessment of high-risk cutaneous stigmata on sonography. Am J Roentgenol 171:1687-1692. https://doi.org/10.2214/ ajr.171.6.9843314

8. Herman TE, Oser RF, Shackelford GD (1993) Intergluteal dorsal dermal sinuses: the role of neonatal spinal sonography. Clin Pediatr (Phila) 32:627-628. https://doi.org/10.1177/0009922893 03201012
9. Sewell MJ, Chiu YE, Drolet BA (2015) Neural tube dysraphism: review of cutaneous markers and imaging. Pediatr Dermatol 32:161-170. https://doi.org/10.1111/pde.12485

10. Schenk JP, Herweh C, Günther P, Rohrschneider W, Zieger B, Tröger J (2006) Imaging of congenital anomalies and variations of the caudal spine and back in neonates and small infants. Eur $\mathrm{J}$ Radiol 58:3-14. https://doi.org/10.1016/j.ejrad.2005.12.004

11. Unsinn KM, Geley T, Freund MC, Gassner I (2000) US of the spinal cord in newborns: spectrum of normal findings, variants, congenital anomalies, and acquired diseases. Radiographics 20:923-938. https://doi.org/10.1148/radiographics.20.4.g00j1 06923

12. Coleman LT, Zimmerman RA, Rorke LB (1995) Ventriculus terminalis of the conus medullaris: MR findings in children. Am J Neuroradiol 16:1421-1426

13. Sigal R, Denys A, Halimi P, Shapeero L, Doyon D, Boudghène F (1991) Ventriculus terminalis of the conus medullaris: MR imaging in four patients with congenital dilatation. AJNR Am J Neuroradiol 12:733-737

14. Tortori-Donati P, Rossi A, Cama A (2000) Spinal dysraphism: a review of neuroradiological features with embryological correlations and proposal for a new classification. Neuroradiology 42:471-491

15. Meyers AB, Chandra T, Epelman M (2017) Sonographic spinal imaging of normal anatomy, pathology and magnetic growing rods in children. Pediatr Radiol 47:1046-1057. https://doi. org/10.1007/s00247-017-3845-6

16. Dick EA, Patel K, Owens CM, De Bruyn R (2002) Spinal ultrasound in infants. Br J Radiol 75:384-392. https://doi.org/10.1259/ bjr.75.892.750384

17. Korsvik HE, Keller MS (1992) Sonography of occult dysraphism in neonates and infants with MR imaging correlation. Radiographics 12:297-298. https://doi.org/10.1148/radiographics.12.2.15614 18

18. Ben-Sira L, Ponger P, Miller E, Beni-Adani L, Constantini S (2009) Low-risk lumbar skin stigmata in infants: the role of ultrasound screening. J Pediatr 155:864-869. https://doi.org/10.1016/j. jpeds.2009.06.003

19. Medina LS (2009) Spinal dysraphism: categorizing risk to optimize imaging. Pediatr Radiol 39:242-246. https://doi. org/10.1007/s00247-008-1115-3

20. Schwartz ES, Rossi A (2015) Congenital spine anomalies: the closed spinal dysraphisms. Pediatr Radiol 45:413-419. https:// doi.org/10.1007/s00247-015-3425-6

21. Herman JM, McLone DG, Storrs BB, Dauser R (1993) Analysis of 153 patients with myelomeningocele or spinal lipoma reoperated upon for a tethered cord. Pediatr Neurosurg 19:243-249

22. McLone DG, Dias M (1991) Complications of myelomeningocele closure. Pediatr Neurosurg 92:267-273 